\title{
EVOLUTION OF TELECOMMUNICATIONS NETWORKS UNDER IMPRECISE DEMANDS
}

\author{
Carlos M. F. Carlson, Hermano M. F. Tavares and José R. F. Formigoni
}

\begin{abstract}
New services and technologies, as well as the very competitive environment, increase the significance of planning the expansion of telecommunications systems. Multiple ways for network evolution and their related cost claim for comprehensive and flexible planning tools. Mathematical models can also be used. However, at planning time there is uncertainty with respect to some data values. Thus, models must incorporate and deal with uncertainty. Keeping this in mind, it is presented a class of models for planning a stage of the evolution of telecommunications networks, namely, the optical serving of business subscribers (key customers). These models accept imprecise demand values, using a fuzzy numberbased approach. It is possible to analyze several aspects of the contest between fiber- and copper-based systems. Enabling the evaluation of the impact of varying demands onto the planned network is also a key feature of the models. A case study with actual data is reported.
\end{abstract}

Keywords: Access networks; planning tools; fuzzy linear programming.

Resumo - O surgimento de serviços e tecnologias aumenta a importância do planejamento da expansão dos sistemas de telecomunicações. A diversidade de maneiras pelas quais a rede pode evoluir, num ambiente competitivo, sugere o uso de ferramentas flexíveis e abrangentes, baseadas em modelos matemáticos e capazes de entender e tratar dados ainda imprecisos. Neste artigo é desenvolvida uma classe de modelos para suportar o planejamento de um estágio da evolução de redes de telecomunicação, qual seja o atendimento de grandes usuários (perfil comercial). Os modelos aceitam valores imprecisos para a demanda, através do conceito de números nebulosos. Torna-se possível analisar vários aspectos da competição entre os sistemas ópticos e aqueles baseados na rede metálica existente. Outra característica importante desses modelos é permitir a avaliação do impacto da variação dos valores de demandas sobre o resultado do planejamento. Um estudo de caso baseado em dados reais é também apresentado.

Palavras Chaves: Rede de acesso; ferramentas de planejamento, programação linear nebulosa.

Carlos M. F. Carlson is at the University Center of Rio Preto (UNIRP), in São José do Rio Preto, Brazil. Hermano M. F. Tavares is at the Electrical and Computer Engineering School, State University of Campinas (FEEC/UNICAMP), in Campinas, Brazil. José R. F. Formigoni is at the Foundation $\mathrm{CPqD}-$ Telecom \& IT Solutions, in Campinas. Brazil. E-mails: cmfcarlson@acm.org, hermano@densis.fee.unicamp.br. reynaldo@cpqd.com.br.

Review coordinated by Max Henrique M. Costa (Ad Hoc Editor) and José Augusto M. Suruagy (Area Editor). Submitted 10/1998; revised 11/1999; accepted 11/2001

\section{INTRODUCTION}

Telecommunications business is significantly changing. Technological evolution makes possible the rise of new, worthy services. The increasing competitive environment forces the operating companies (Telcoes) to look for solutions that guarantee both market acceptance and relevant revenues.

The use of optical fibers as transmission medium in telecommunications networks tends to be dominant when there is a lot of information to be carried (as it is the case of several services) and high reliability is needed. In the beginning, optical fibers were applied to the transport network. In the last few years, access networks also started to use fibers. In Brazil. Telcoes are installing fibers in the access network in a step-by-step way. The first step is devoted to the business subscribers (key customers whose amount of services require $2 \mathrm{Mbps}$ or higher transmission rates). These optical systems are named BOAN's (BusinessOriented Access Networks) [1]. Next, the copper-based feeder network will either evolve to be an optical network or adopt a hybrid solution (a mix of copper and coaxial cables, optical fibers and wireless systems). Finally, in the long term fibers may be utilized in the distribution network. reaching in this way all the subscribers.

Planning the access network evolution is a relevant activity, given that this network implies the major part of system cost. The planning is also complex, by involving choices among several topologies and technologies. As a matter of fact, there is an enormous amount of fiber-based equipment. Moreover, vendors announce equipment to carry high bit-rate signals through the existing copper cables (under a set of conditions). On the other hand, there are situations where the Fixed Wireless Access (FWA) is suitable. The planner may choose a solution based on one or more topologies and technologies.

Complexity and relevance of the access network planning leads to the use of mathematical models. Nevertheless, it is a very large activity, and it is convenient to tackle each problem in a separate way. In this paper, we concentrate on the first problem (planning of serving business subscribers either by BOAN's or by copper-based alternatives). Equipment allocation and sizing in order to carry the demand up to the central office is the decision to be made.

In earlier works, Formigoni et al. [2,3] have proposed a methodology and mathematical models for the BOAN's planning. These works had as direction to help the planner in allocating and sizing BOAN equipment while searching minimal cost. Of course, topological constraints, as well as demands, capacities and available technologies were modeled.

However, many of the needed data to the planning is uncertain, which is expected in a changing setting, as is the 
telecommunications business. Models must be flexible, and incorporate this uncertainty. Therefore, the models of the above works were modified in order to deal with imprecise data. Carlson et al. [4] have accommodated both flexible budget limits and tolerances with respect to the effective amount of carried demand, in a fuzzy-set approach $[5,6]$. In [7], the same authors have proposed a way to allow uncertainty on the equipment costs in the BOAN's planning. The approach was extended [8] in order to include nonoptical systems as participants of the decision-making process. These works have used concepts of fuzzy numbers $[5,8,9,10]$.

A source of uncertainty remains yet to be addressed: the demand to the services. There is not a forecasting method that establishes in a precise way the demand levels to be used as data to the planning. In turn, planning results may be dependent on variations of these values. Models that can anticipate solutions for different demand settings are needed. Again, using fuzzy sets and fuzzy numbers seems to be promising

In this paper we present new models for helping the planning of serving business subscribers, given the uncertainty with respect to the demand values. We concisely describe, in section 2 , the telecommunications system under consideration and the major ways of meeting the demand of business subscribers. In section 3 an "exact" mixed linear model, with binary variables, is built. In section 4 we incorporate uncertainty to the model and we discuss some alternative methods to solve the mathematical problem with fuzzy numbers. Finally, in section 5 we report an application to an actual network of a Brazilian city.

\section{TELECOMMUNICATIONS SYSTEMS}

\subsection{TERMINOLOGY}

This work concerns the cable-based portion of access telecommunications networks. In such a system (Fig. 1), each user (subscriber) is linked to a central office (CO).

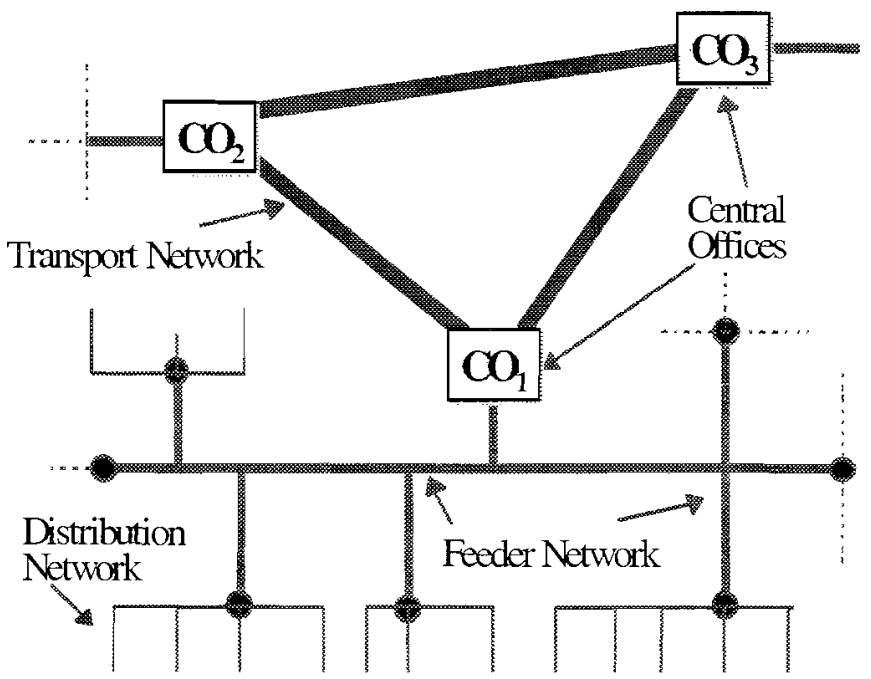

Figure 1. Access network and transport network.

The link generally utilizes small-capacity twisted copper wire cables in order to connect the subscriber's home to a concentration point (to where other subscribers are also linked). This (aerial) part of the system is called the distribution network.

From the concentration point, the (underground) feeder network links the subscribers to the $\mathrm{CO}$ by using largercapacity cables or multiplexed lines. Together, the distribution network and the feeder network constitute the local access network, or outside plant.

At the $\mathrm{CO}$, switching equipment makes possible for each subscriber to communicate with all others: if two subscribers do not belong to the same CO, they must be linked by the transport network, which interconnects the $\mathrm{CO}$ s.

\subsection{SERVING BUSINESS SUBSCRIBERS}

A business subscriber (or a subscriber group) asks for services which need transmission rates of $2 \mathrm{Mbps}$ or higher. The objective of a Business-oriented Access Network (BOAN) is to meet the demand of business subscribers. A BOAN uses only optical fibers in a Fiber-to-the-Office (FTTO) architecture. Because its users require high transmission rates and may generate important revenues, a BOAN must be a reliable, high-quality services network [1]. Routing demands to the $\mathrm{CO}$ by a BOAN requires allocating and sizing equipment, a task which is the goal of this work.

This task involves a choice from among various possible topologies with different technologies. Some equipment technologies which can be used in a BOAN are PDH (Plesiochronous Digital Hierarchy), SDH (Synchronous Digital Hierarchy), TDM/TDMA (Time Division Multiple Access), and ATM (Asynchronous Transfer Mode). The use of the following basic topologies is foreseen: Single Star, Active and Passive Double Star, Ring/Star, and Bus/Star. The eventual solution may utilize one or more of these topologies and/or technologies.

There is an alternative way of meeting the demand, which is based on HDSL (High bit-rate Digital Subscriber Line) technology [11]. This kind of equipment allows, under some conditions, high-rate bi-directional transmission while using copper wire cables. Limits on using copper are worst when high transmission rates are needed. Therefore, there are some constraints, as the distance from the subscriber to the $\mathrm{CO}$, the physical connections, and others.

\section{PLANNING MODEL}

For planning purposes, we assume that each business subscriber is linked to only one CO. Thus, each $\mathrm{CO}$ area is treated independently. An oriented graph [12] represents the "demand points" (source nodes), the CO (sink node), and the interlinking arcs. By using this graph, we can formulate a mixed linear mathematical model. The model has binary variables and real variables. The binary variables correspond with the decision about installing or not the optical transmission equipment, while the real variables correspond to the flow in each arc (in other words, to the number of 2-Mbps channels carried by the deployed equipment). The use of copper-wire cables by HDSL equipment is allowed only at arcs that connect demand nodes to the $\mathrm{CO}$ node. Whenever used, HDSL-based links 
need equipment both at the subscriber and at the CO (one piece of HDSL equipment is able to carry only one 2-Mbps channel).

The model, based on [8], is:

Minimize:

$$
Z=\sum_{(i, j) \in A} \sum_{n \in N_{i j}} c_{i j n} x_{i j n}+\sum_{m \in M} c_{m} w_{m}+\sum_{h \in H} c_{h} s_{h}
$$

subject to:

$$
\begin{gathered}
\sum_{j \in J 1} y_{i j}-\sum_{j \in J 2} y_{j i}=d_{i}, \forall i \in I \\
\sum_{n \in N_{i j}} C_{a p_{n}} x_{i j n} \geq y_{i j}, \forall(i, j) \in A-R \\
w_{m}-x_{l n n} \geq 0, \forall n \in N_{l m}, \forall l \in J 2 \\
\sum_{n \in N_{h 0}} C_{a p_{n}} x_{h 0 n}+s_{h} \geq y_{h 0}, \forall h \in H
\end{gathered}
$$

where:

$$
\begin{aligned}
& A \text { - set of network arcs } \\
& N_{i j} \text { - set of candidate facilities (optical transmission } \\
& \text { systems) in arc } i j \\
& c_{i j n} \text { - cost of type } n \text { optical facility, whenever candidate in }
\end{aligned}
$$

In the model, the objective (1) is the total cost of equipment. We assume in this work that all costs are precisely known. We do not consider the cost of the transmission medium, neither fiber nor copper, because it is lower than the equipment cost and its optimization might be insignificant. Optical equipment has fixed cost and modular capacity, as well as remote units do. HDSL has only variable cost. Equations (2) give the flow balance for each node. Constraints (3) and (5) describe equipment sharing among several users, and force the flow in each arc to respect the transmission capacity of such an arc. Constraints (4) refer to the use of remote units.

The representation of SDH unidirectional rings deserves minor adjustments. For each ring, a dummy node is used to collect the demands of the participant nodes. The collected demand is sent to the $\mathrm{CO}$ by an artificial arc. The cost of the equipment to be installed at a demand node and its capacity is associated with the arc linking the demand node to the dummy node. The cost of the equipment to be installed at a $\mathrm{CO}$ and the total capacity of the unidirectional ring is associated with the arc linking the dummy node to the $\mathrm{CO}$ node.

It is not difficult to incorporate some other planning needs, such as costs aspects, preferences on some technologies/topologies, safety requirements, and even notmentioned topologies.

Cost-minimization models for planning of telecommunications copper-based networks were extensively discussed in [13]. A remarkable computational tool suitable to this type of network was documented in [14]. The deployment of optical fibers in the access network joined the literature mainstream by the middle of the 90's. The EURESCOM Consortium [15] developed several studies on the subject. While emphasizing technoeconomical aspects, EURESCOM's models often assume simplified representations to the network and take into account just one technology at a time. Nowadays, due the progressive importance of market features, models driven by revenue maximization can be found. For instance, DeSousa et al. [16] present a general formulation that can be adapted to several optical technologies. In their work, as well as in the above model (1)-(5), the competition between optical and copper-based technologies is fully addressed, along with a realistic graph representation to the network.

\section{REPRESENTATION OF UNCERTAINTY CONCERNING THE DEMAND}

\subsection{GENERAL CONSIDERATIONS}

If the values to be adopted as demand indicators at the nodes are imprecise at the planning time, model (1)-(5) must be modified in order to furnish equipment deployment alternatives that remain useful even under uncertainty. In other words, the model must accept uncertain demand values.

In a typical setting, the planner has a good idea about the range of probable values, but adopting an exact (unique) value means narrowing the perception of the problem and its variants. If inside this range, which represents demands, the planner can distinguish values with greater or lesser possibility, the concept of fuzzy numbers may be helpful.

A fuzzy number is defined as a fuzzy set with two properties: it is normalized and convex [5]. If the range of demand values can be viewed in such a way, fuzzy numbers may be used to represent the uncertainty about demand.

Let us associate to each demand node $i$ a fuzzy set $\tilde{D}_{i}=(d i, D i, \bar{d} i)$ defined as "the set of possible values of the 
node demand". Let us also assume that the membership function of the demand values to the fuzzy set is as follows (see Fig. 2):

$$
\mu_{\tilde{D}_{i}}(u)= \begin{cases}0, & \text { if } d_{i}<\underline{d}_{i} \\ \frac{d_{i}-\underline{d}_{i}}{D_{i}-\underline{d}_{i}}, & \text { if } \underline{d}_{i} \leq d_{i} \leq D_{i} \\ \frac{\bar{d}_{i}-d_{i}}{\bar{d}_{i}-D_{i}}, & \text { if } D_{i} \leq d_{i} \leq \bar{d}_{i} \\ 0, & \text { if } \bar{d}_{i}<d_{i}\end{cases}
$$

Defined this way, $\tilde{D}_{i}$ is a triangular fuzzy number (it is not mandatory that the triangle be an isosceles one) whose value with higher membership is $D_{i}$. This definition could be changed to represent a trapezoidal fuzzy number, for instance. In this work we adopt triangular fuzzy numbers.

If the demand is now given by a fuzzy number, flowbalance equation (2) at each node is rewritten as:

$$
\sum_{j \in J 1} y_{i j}-\sum_{j \in J 2} y_{j i}=\widetilde{D}_{i}, \forall i \in I
$$

Fuzzy numbers may change substantially the way of solving the equations. Two approaches are mostly used:

a) replacement of the fuzzy number by a (non-fuzzy) value which is an equivalent value under some criterion;

b) replacement of the fuzzy number by a parameter which leads the problem to an easier solving domain while maintaining the uncertainty given by the former fuzzy number.

\subsection{REPLACEMENT BY NON-FUZZY VALUES}

Among the available techniques we found the so-called "defuzzyfication", which consists in finding a "work value" to the fuzzy number under consideration. "Defuzzyfication" functions can be used. for instance, in ordering (ranking) fuzzy numbers [9].

Let us use as example one of the functions given by Yager [17], the "third Yager function" (or Yager-3), which is defined as:

$$
f_{Y}\left(\tilde{D}_{i}\right)=\int_{0}^{1} M(\alpha) d_{\alpha}
$$

where $M(\alpha)$ is the mean value of the elements for all the possible $\alpha$-cuts. If, as in our case, we have a triangular fuzzy number:

$$
\begin{aligned}
f_{Y}\left(\tilde{D}_{i}\right)=D_{i_{e q}} & =D_{i}+\frac{1}{4}\left(\bar{d}_{i}+\underline{d}_{i}-2 D_{i}\right) \\
& =\frac{1}{4}\left(\bar{d}_{i}+\underline{d}_{i}+2 D_{i}\right)
\end{aligned}
$$

In practice, this implies to adopt node flow-balance equations as:

$$
\sum_{j \in J 1} y_{i j}-\sum_{j \in J 2} y_{j i}=D_{i_{e q}}, \forall i \in I
$$

Given that $D_{i e q}$ are exact (non-fuzzy) values, the model, after replacing ( 7 ) by (10), is the same as before; uncertainties are dropped by using equivalent values. This is a simplifying approach, but has the inconvenient of presenting only one exact (crisp) solution to a problem with fuzzy data.

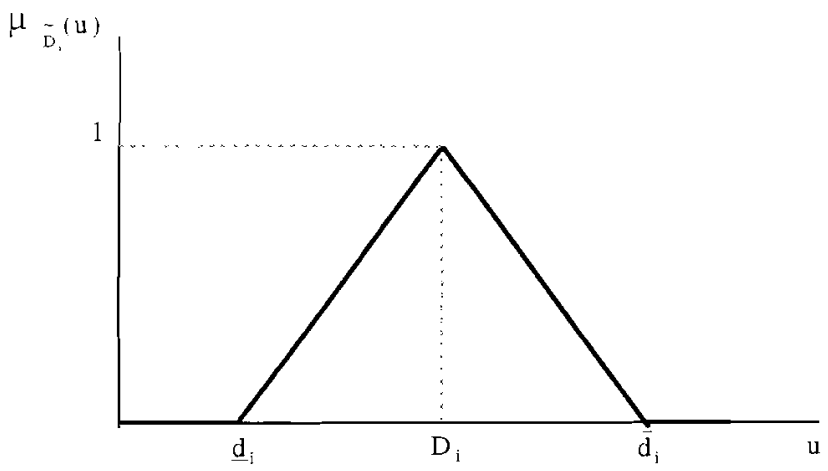

Figure 2. Triangular fuzzy number.

Furthermore, we know that $D_{i c q}$ values are not necessarily integrals, what looks something strange to demand. Clearly, it is possible to oblige $D_{i e q}$ values to be integers; however, this implies a heavier solving method, maybe an unnecessary (and undesirable) effort at our planning level.

\subsection{REPLACEMENT BY PARAMETRIC VALUES}

This approach seeks to make the problem easier while respecting the uncertainty of data. The idea is to utilize a parametric substitute of the fuzzy number. To our problem, the parameter variation allows to analyze different settings for the demand value. An evident advantage is that the solution to the problem also depends on the parameter: the solution can be interpreted, in each case, from the meaning of the parameter.

Adamo [18] presents a parametric function to determine the equivalent of the fuzzy number:

$$
f_{\alpha}\left(\tilde{D}_{i}\right)=\max \left\{d_{i} \mid \mu_{\tilde{D}_{i}}\left(d_{i}\right) \geq \alpha\right\}
$$

with $\alpha \in[0,1]$.

In the triangular case (Fig. 3), Adamo's equivalent is:

$$
f_{\alpha}\left(\tilde{D}_{i}\right)=D_{i}+\left(\bar{d}_{i}-D_{i}\right)(1-\alpha)
$$

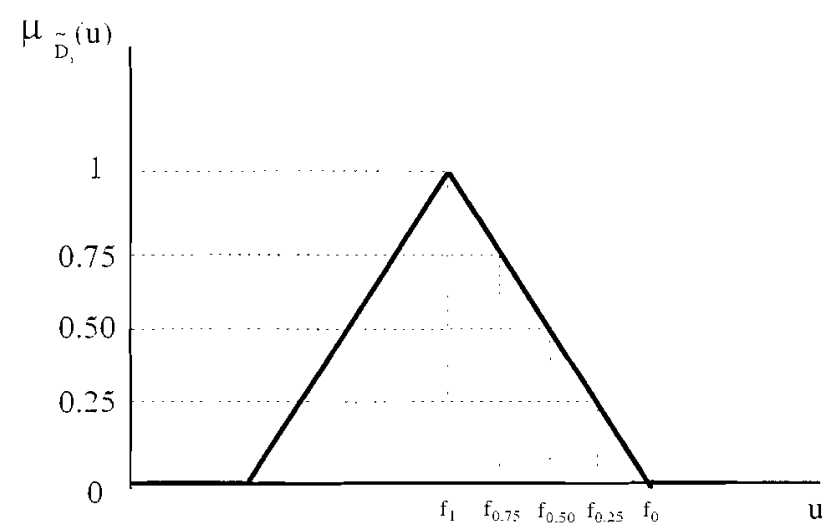

Figure 3. Adamo's equivalent. 
The parameter $\alpha$ indicates, to Adamo, the confidence level on the adopted values; particularly, the fuzzy number is reduced to an interval from which we take the upper limit as our work value.

Equations (7) become:

$$
\sum_{j \in J 1} y_{i j}-\sum_{j \in J 2} y_{j i}=D_{i}+\left(\bar{d}_{i}-D_{i}\right)(1-\alpha), \forall i \in I
$$

with $\alpha \in[0,1]$.

The model with equations (13) is a parametric one. Now, it is possible to analyze how the planning results (equipment, needed capacities, etc. and the respective cost) vary with the parametric variation of the demand.

\subsection{PARAMETERS AND TOLERANCES}

Still based on using parameters, another approach to the subject is presented by Delgado et al. [19] and by Campos and Verdegay [20]. The starting point of the approach is to think that, in an equation or inequality where there are fuzzy numbers (that is, in a comparison of fuzzy numbers) it is always possible some violation of the constraint. Therefore, comparison is made by assuming some tolerance (which in turn is also a fuzzy number). Generically:

$$
\tilde{\mathbf{A}} \mathbf{x} \prec \tilde{\mathbf{B}}+\tilde{\mathbf{T}}(1-\lambda)
$$

with $\lambda \in(0,1]$, where $\tilde{\mathbf{A}}=(\underline{\mathbf{a}}, \mathbf{A}, \overline{\mathbf{a}})$ and $\widetilde{\mathbf{B}}=(\underline{\mathbf{b}}, \mathbf{B}, \overline{\mathbf{b}})$ are arrays of triangular fuzzy numbers. $\widetilde{\mathbf{T}}=(\mathbf{t}, \mathbf{T}, \overline{\mathbf{t}})$ is the tolerance array with respect to the compliance of the comparison, and it is also an array of triangular fuzzy number. The symbol $\prec$ stands for any relationship between fuzzy numbers (in practice, $\prec$ is replaced by any method for comparing fuzzy numbers).

Taking for instance the Yager-3 function, formerly presented, and assuming an inequality of $\leq$ type, (14) would be equivalent to:

$$
(\overline{\mathbf{a}}+\underline{\mathbf{a}}+2 \mathbf{A}) \mathbf{x} \leq(\overline{\mathbf{b}}+\underline{\mathbf{b}}+2 \mathbf{B})+(\overline{\mathbf{t}}+\underline{\mathbf{t}}+2 \mathbf{T})(1-\lambda)
$$

with $\lambda \in(0,1]$.

If the comparison method is Adamo's one, then for some pre-defined $\alpha \in[0,1]$ we would have:

$$
\begin{aligned}
{[(1-\alpha) \overline{\mathbf{a}}+\alpha \mathbf{A}] \mathbf{x} \leq } & {[(1-\alpha) \overline{\mathbf{b}}+\alpha \mathbf{B}]+} \\
& {[(1-\alpha) \overline{\mathbf{t}}+\alpha \mathbf{T}](1-\lambda) }
\end{aligned}
$$

with $\lambda \in(0,1]$.

It means that, in a general manner, with $\lambda \in(0,1]$ :

$$
f(\tilde{\mathbf{A}}) \mathbf{x} \leq f(\tilde{\mathbf{B}})+f(\tilde{\mathbf{T}})(1-\lambda)
$$

When we have an equation (=) involving fuzzy numbers, two inequalities can replace such an equation:

$$
\left\{\begin{array}{l}
f(\tilde{\mathbf{A}}) \mathbf{x} \leq f(\tilde{\mathbf{B}})+f(\widetilde{\mathbf{T}})(1-\lambda) \\
f(\tilde{\mathbf{A}}) \mathbf{x} \geq f(\tilde{\mathbf{B}})-f(\widetilde{\mathbf{T}})(1-\lambda)
\end{array}\right.
$$

with $\lambda \in(0,1]$.

In our problem, equations (7) present fuzzy numbers only at the right-hand side (demands). Nevertheless, non-fuzzy numbers at the left-hand size can be viewed as particular fuzzy numbers as well:

$$
\sum_{j \in J 1} \tilde{1} y_{i j}-\sum_{j \in J 2} \tilde{1}_{y j}=\tilde{D}_{i}, \forall i \in I
$$

Assuming $\tilde{T}_{i}$ as the tolerance with respect to the compliance of each equation ( $\tilde{T}_{i}$ is a triangular fuzzy number similar to $\tilde{D}_{i}$ ), the equations (7) become, using Yager-3 ranking function, with $\lambda \in(0,1]$ :

$$
\left\{\begin{aligned}
\sum_{j \in J 1} 1 y_{i j}-\sum_{j \in J 2} 1 y_{j i} \leq & \frac{1}{4}\left(\bar{d}_{i}+\underline{d}_{i}+2 D_{i}\right)+ \\
& \frac{1}{4}\left(\bar{t}_{i}+\underline{t}_{i}+2 T_{i}\right)(1-\lambda) \\
\sum_{j \in J 1} 1 y_{i j}-\sum_{j \in J 2} 1 y_{j i} \geq & \frac{1}{4}\left(\bar{d}_{i}+\underline{d}_{i}+2 D_{i}\right)- \\
& \frac{1}{4}\left(\bar{t}_{i}+\underline{t}_{i}+2 T_{i}\right)(1-\lambda)
\end{aligned}\right.
$$

If we use Adamo's ranking function, we will have:

$$
\left\{\begin{aligned}
\sum_{j \in J 1} 1 y_{i j}-\sum_{j \in J 2} 1 y_{j i} \leq & {\left[(1-\alpha) \bar{d}_{i}+\alpha D_{i}\right]+} \\
& {\left[(1-\alpha) \bar{t}_{i}+\alpha T_{i}\right](1-\lambda) } \\
\sum_{j \in J 1} 1 y_{i j}-\sum_{j \in J 2} 1 y_{j i} \geq & {\left[(1-\alpha)_{\bar{d}_{i}}+\alpha D_{i}\right]-} \\
& {\left[(1-\alpha) \bar{t}_{i}+\alpha T_{i}\right](1-\lambda) }
\end{aligned}\right.
$$

with $\lambda \in(0,1]$ and $\alpha \in[0,1]$ pre-defined by the planner.

Both methods keep the linearity of the original problem, which is a desirable feature. Clearly, other ranking methods can be used (see, for instance, Campos and Verdegay [20]).

\section{APPLICATION}

\subsection{GENERAL DATA}

We utilize as an example a network that corresponds to a part of the business area of a big Brazilian city. Fig. 4 shows the network, with one $\mathrm{CO}$ and 16 demand nodes.

Demand values, given in 2-Mbps channels, are listed on Table 1. The (uncertain) demand at each node is represented by triangular fuzzy numbers. All the triangles are symmetric, but this is not mandatory. Total demand, summation of triangular fuzzy numbers, is also a triangular fuzzy number [5]. We may represent it as: $\tilde{D}_{t o t}=(125$, $185,245)$.

We assume in the study that the meeting of the demand can be achieved by equipment of PDH and SDH technology (optical systems under single star or ring/star topology), as well as HDSL equipment (using copper in point-to-point links). Equipment's capacities, also given in 2-Mbps channels, and other features are in Table 2.

Costs of PDH and HDSL equipment are related to both ends of the link. SDH equipment is used on 155-Mbps 
unidirectional rings (each ring can carry 63 2-Mbps cliannels), and it is mandatory to install an ADM-63 equipment at the $\mathrm{CO}$ for each ring. We adopt the PDH $1 \mathrm{x}$ $34 \mathrm{Mbps}$ equipment cost as our reference. HDSL equipment does not have fixed cost, because it is not modular (one piece of equipment is required to meet one unit of 2-Mbps demand).

\begin{tabular}{|c|r|r|r|c|r|r|r|}
\hline Node & \multicolumn{1}{|c}{ D } & D & $\overline{\mathbf{d}}$ & Node & \multicolumn{1}{c}{$\mathbf{d}$} & \multicolumn{1}{c|}{$\mathbf{D}$} & $\overline{\mathbf{d}}$ \\
\hline 09 & 24 & 32 & 40 & 23 & 5 & 8 & 11 \\
\hline $\mathrm{I} 4$ & 5 & 8 & 11 & 24 & 4 & 7 & 10 \\
\hline 17 & 2 & 4 & 6 & 25 & 8 & 12 & 16 \\
\hline 18 & 8 & 12 & 16 & 26 & 27 & 35 & 43 \\
\hline 19 & 10 & 14 & 18 & 36 & 3 & 5 & 7 \\
\hline 20 & 3 & 6 & 9 & 38 & 2 & 4 & 6 \\
\hline 21 & 5 & 8 & 11 & 39 & 1 & 3 & 5 \\
\hline 22 & 6 & 10 & 14 & 40 & 12 & 17 & 22 \\
\hline
\end{tabular}

Table 1. Considered demands.

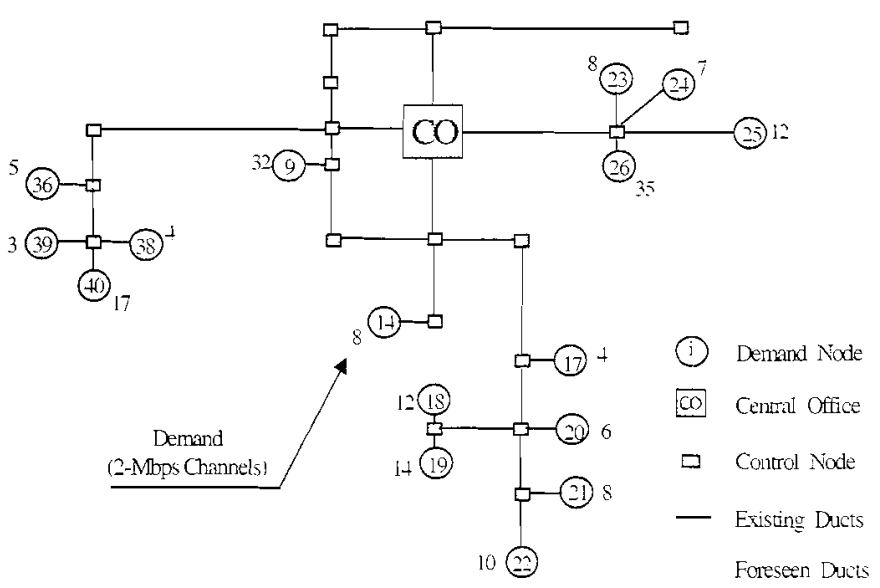

Figure 4. Network to the application.

\begin{tabular}{|l|c|c|c|}
\hline Equipment/Technology & Medium & Capacity & Cost \\
\hline $1 \times 34$ Mbps (PDH) & fiber & 16 & 1.000 \\
\hline $2 \times 34$ Mbps (PDH) & fiber & 32 & 1.820 \\
\hline ADM 21 channels (SDH) & fiber & 21 & 0.740 \\
\hline ADM 42 channels (SDH) & fiber & 42 & 0.820 \\
\hline ADM 63 channels (SDH) & fiber & 63 & 0.900 \\
\hline HDSL & copper & 1 & 0.125 \\
\hline
\end{tabular}

Table 2. Equipment data.

\subsection{CANDIDATE SYSTEMS}

We assume that the demand at each node can be met either by PDH, SDH or HDSL equipment. Given that the maximal total demand is 245 , we verify that $4 \mathrm{SDH}$ rings may be enough to meet that demand $(4 \times 63=252>245)$. Of course, this depends on the candidates (possibilities of node-ring allocations). As the higher membership value to the total demand is 185 , we establish 4 candidate rings (Table 3). To each node is offered equipment whose capacity is compatible with the demand levels from Table 1.

\begin{tabular}{|c|l|}
\hline Ring & Possible nodes \\
\hline 1 & $9,36,38,39,40$ \\
\hline 2 & $14,17,18,19,20,21,22$ \\
\hline 3 & $23,24,25,26$ \\
\hline 4 & $14,23,26,36,38$ \\
\hline
\end{tabular}

Table 3. Candidate rings.

\subsection{ANALYSIS OF OPTIMAL BUDGETS TO MINIMAL AND MAXIMAL DEMANDS}

If the adopted value for the demand at each node is the least value expressed by its membership function, solving the problem will result in the minimal network cost. It means that, if we do not spend at least this amount of money, some demand will certainly remain unmet, whatever is its actual value. Fig. 5 (in which the network comes in a way to help visualization) presents the network solution under these conditions.

On the other hand, if we use the maximal possible value for the demand at each node, we obtain the upper limit to the budget. It will never be necessary to spend more than that amount of money to meet the demand (see Fig. 6).

For comparison purposes. we also present in Fig. 7 the network solution when the demand is fixed and equal, at each node, to the value with higher membership $\left(D_{i}\right)$. As fuzzy numbers are symmetric triangles, the demand is the mean (expected) value.

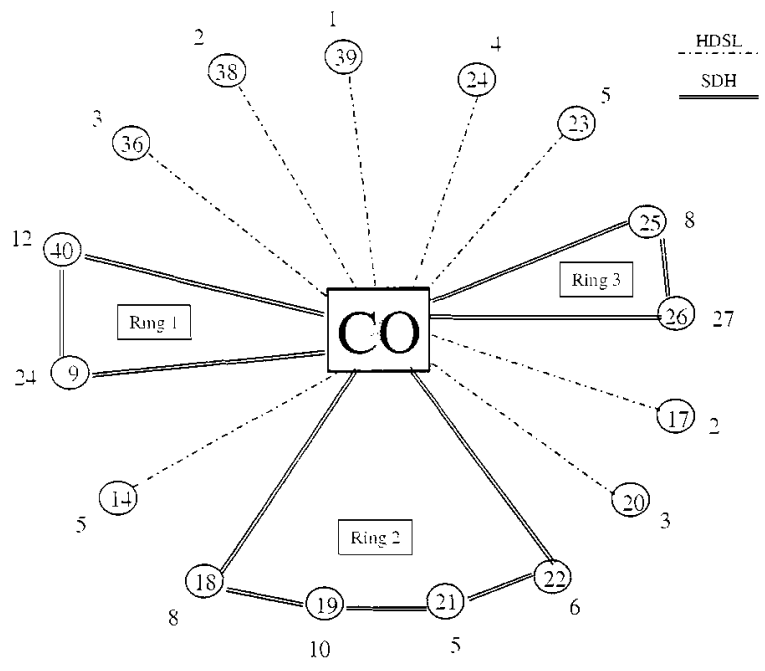

Figure 5. Network for minimal demand setting.

Table 4 contains the amount of deployed equipment, the solution costs at each setting, and a simplified calculation of the cost/demand ratio. This way, planner knows the limits of the budget and has a good notion of how is (or is not) important to increase the investment. In the example, in order to deal with a demand increase of almost $100 \%$ $(245 / 125)$, the investment is $30 \%$ greater $(15.51 / 11.905)$. It is also interesting to observe the differences among the topologies of each setting. 


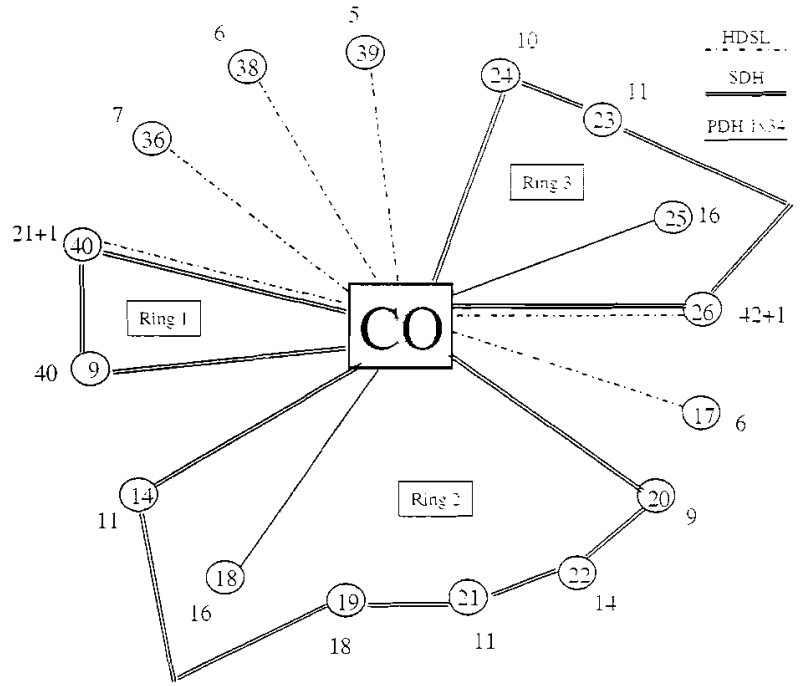

Figure 6. Network for maximal demand setting.

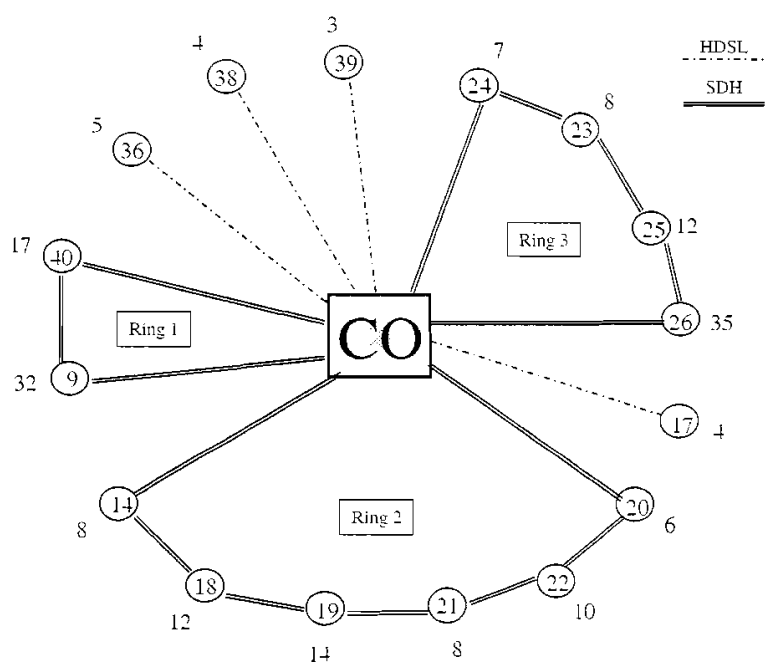

Figure 7. Network for expected demand setting.

\begin{tabular}{|l|c|c|c|}
\cline { 2 - 4 } \multicolumn{1}{c|}{} & $\begin{array}{c}\text { Minimal } \\
\text { demand }\end{array}$ & $\begin{array}{c}\text { Maximal } \\
\text { demand }\end{array}$ & $\begin{array}{c}\text { Expected } \\
\text { demand }\end{array}$ \\
\hline Total demand & 125 & 245 & 185 \\
\hline $\begin{array}{l}\text { PDH Ix34Mbps } \\
\text { systens }\end{array}$ & - & 2 & - \\
\hline $\begin{array}{l}\text { PDH 2x34Mbps } \\
\text { systems }\end{array}$ & - & - & - \\
\hline SDH rings & 3 & 3 & 3 \\
\hline HDSL systems & 25 & 26 & 16 \\
\hline Total cost & 11.905 & 15.510 & 13.740 \\
\hline Cost/demand ratio & 0.095 & 0.063 & 0.074 \\
\hline
\end{tabular}

Table 4. Summary of results.

\subsection{SOLUTION WITH FUZZY DEMAND}

Among the approaches we described in the former section, let us choose the one that uses parameters and tolerances to represent the fuzzy numbers of the problem.
Such an approach (section +.4 ) requires the definition of tolerances (which are also triangular fuzzy numbers) for each demand node. These tolerances are on Table 5, as well as the respective Adamo s equivalents, denoted by $T_{\text {Ad }}$ (we pre-define the level of confidence $\alpha=0.5$ ). Only the Adamo's equivalent will be studied. For the sake of clearness, we state again the demand triangles and their equivalents $\left(D_{+a}\right)$.

\begin{tabular}{|c|r|r|r|r|r|r|r|r|}
\hline Node & \multicolumn{1}{c|}{$\underline{\mathbf{d}}$} & \multicolumn{1}{c|}{$\mathbf{D}$} & $\overline{\mathbf{d}}$ & $\mathbf{D}_{\text {Ad }}$ & \multicolumn{1}{|}{$\underline{\mathbf{t}}$} & $\mathbf{T}$ & $\overline{\mathbf{t}}$ & $\mathbf{T}_{\mathbf{A d}}$ \\
\hline 09 & $\mathbf{2 4}$ & 32 & 40 & 36.0 & 5 & 8 & 11 & 9.5 \\
\hline 14 & 5 & 8 & 11 & 9.5 & 1 & 2 & 3 & 2.5 \\
\hline 17 & 2 & 4 & 6 & 5.0 & 0 & 1 & 2 & 1.5 \\
\hline 18 & 8 & 12 & 16 & 14.0 & 1 & 3 & 5 & 4.0 \\
\hline 19 & 10 & 14 & $\mathbf{1 8}$ & 16.0 & 2 & 4 & 6 & 5.0 \\
\hline 20 & 3 & 6 & 9 & 7.5 & 1 & 2 & 3 & 2.5 \\
\hline 21 & 5 & 8 & 11 & 9.5 & 1 & 2 & 3 & 2.5 \\
\hline 22 & 6 & 10 & 14 & 12.0 & 1 & 3 & 5 & 4.0 \\
\hline 23 & 5 & 8 & 11 & 9.5 & 1 & 2 & 3 & 2.5 \\
\hline 24 & 4 & 7 & 10 & 8.5 & 1 & 2 & 3 & 2.5 \\
\hline 25 & 8 & 12 & 16 & 14.0 & 1 & 3 & 5 & 4.0 \\
\hline 26 & 27 & 35 & 43 & 39.0 & 5 & 9 & 13 & 11.0 \\
\hline 36 & 3 & 5 & 7 & 6.0 & 1 & 2 & 3 & 2.5 \\
\hline 38 & 2 & 4 & 6 & 5.0 & 0 & 1 & 2 & 1.5 \\
\hline 39 & 1 & 3 & 5 & 4.0 & 0 & 1 & 2 & 1.5 \\
\hline 40 & 12 & 17 & 22 & 19.5 & 3 & 5 & 7 & 6.0 \\
\hline
\end{tabular}

Table 5. Demand values and their tolerances at each node.

Taking for instance node 23 , let us see what means using fuzzy numbers to represent its demand. Assuming node 0 as the $\mathrm{CO}$ and considering the candidate equipment at node 23 , the flow-balance equation is, according to (7):

$$
Y_{23,0}^{P D H}+Y_{23,0}^{H D S L}+Y_{23, \text { Ring } 3}^{S D H}+Y_{23, \text { Ring } 4}^{S D H}=\tilde{8}
$$

Replacing this equation by those ones obtained by using Adamo's equivalent (21), and considering the values on Table 5, we have:

$$
\left\{\begin{array}{l}
Y_{23.0}^{P D H}+Y_{23.0}^{H D S L}+Y_{23 . \text { Ring } 3}^{S D H}+Y_{23 . \text { Ring } 4}^{S D H} \leq 9.5+2.5(1-\lambda) \\
Y_{23.0}^{P D H}+Y_{23.0}^{H D S L}+Y_{23 . \text { Ring } 3}^{S D H}+Y_{23 . \text { Ring } 4}^{S D H} \geq 9.5-2.5(1-\lambda)
\end{array}\right.
$$

with $\lambda \in(0,1]$.

This modification must be applied to all balance-flow equations of demand nodes. The problem becomes parametric on $\lambda$. Distinct values for $\lambda$ may lead to different solutions (costs and topologies). Then, let us inspect the effect of varying $\lambda$ onto the solution, starting from $\lambda=0$ and adopting Adamo's equivalent. As we have already pointed out in the previous section, we will assume that demands may take non-integral values.

Fig. 8 presents the topology of minimum cost (13.250) for $\lambda=0$. As demand values are taken from intervals, we show in the figure the maximum total demand that can be met by the chosen equipment. Table 6 lists, for each node, the intervals from which demands are taken and the installed equipment. PDH technology was not used. 


\begin{tabular}{|c|c|c|c|}
\hline Node & {$\left[\mathrm{D}_{\mathrm{Ad}}-\mathbf{T}_{\mathrm{Ad}} ; \mathrm{D}_{\mathrm{Ad}}+\mathbf{T}_{\mathrm{Ad}}\right]$} & $\mathrm{SDH}$ & HDSL \\
\hline 09 & {$[26.5 ; 45.5]$} & $\begin{array}{c}1 \times \mathrm{ADM}-42 \\
\text { (ring } 1 \text { ) }\end{array}$ & - \\
\hline 14 & {$[7.0 ; 12.0]$} & $\begin{array}{c}1 \times \mathrm{ADM}-21 \\
\text { (ring 2) }\end{array}$ & - \\
\hline 17 & {$[3.5: 6.5]$} & - & 3.5 \\
\hline 18 & {$[10.0 ; 18.0]$} & $\begin{array}{c}1 \times \mathrm{ADM}-21 \\
\text { (ring 2) }\end{array}$ & - \\
\hline 19 & {$[11.0 ; 21.0]$} & $\begin{array}{c}1 \times \mathrm{ADM}-21 \\
\text { (ring 2) }\end{array}$ & - \\
\hline 20 & {$[5.0 ; 10.0]$} & - & 5.0 \\
\hline 21 & {$[7.0 ; 12.0]$} & $\begin{array}{c}1 \times \text { ADM-21 } \\
\text { (ring 2) }\end{array}$ & - \\
\hline 22 & {$[8.0: 16.0]$} & $\begin{array}{c}1 \times \text { ADM-21 } \\
\text { (ring 2) }\end{array}$ & - \\
\hline 23 & {$[7.0 ; 12.0]$} & $\begin{array}{c}1 \times \mathrm{ADM}-21 \\
\text { (ring 3) }\end{array}$ & - \\
\hline 24 & {$[6.0: 11.0]$} & $\begin{array}{c}1 \times \mathrm{ADM}-21 \\
\text { (ring 3) }\end{array}$ & - \\
\hline 25 & {$[10.0 ; 18.0]$} & $\begin{array}{c}1 \times \text { ADM-21 } \\
\text { (ring 3) }\end{array}$ & - \\
\hline 26 & {$[28.0: 50.0]$} & $\begin{array}{c}1 \times \mathrm{ADM}-42 \\
\text { (ring } 3 \text { ) }\end{array}$ & - \\
\hline 36 & {$[3.5: 8.5]$} & - & 3.5 \\
\hline 38 & {$[3.5: 6.5]$} & - & 3.5 \\
\hline 39 & {$[2.5 .5 .5]$} & - & 2.5 \\
\hline 40 & {$[13.5 ; 25.5]$} & $\begin{array}{c}1 \times \text { ADM-21 } \\
\text { (ring 1) }\end{array}$ & - \\
\hline Ring 1 & - & $1 \times$ ADM-63 & - \\
\hline Ring 2 & - & $1 \times$ ADM-63 & - \\
\hline Ring 3 & - & $1 \times$ ADM-63 & - \\
\hline Ring 4 & - & - & - \\
\hline
\end{tabular}

Table 6. Summary of the solution for $\lambda=0$.

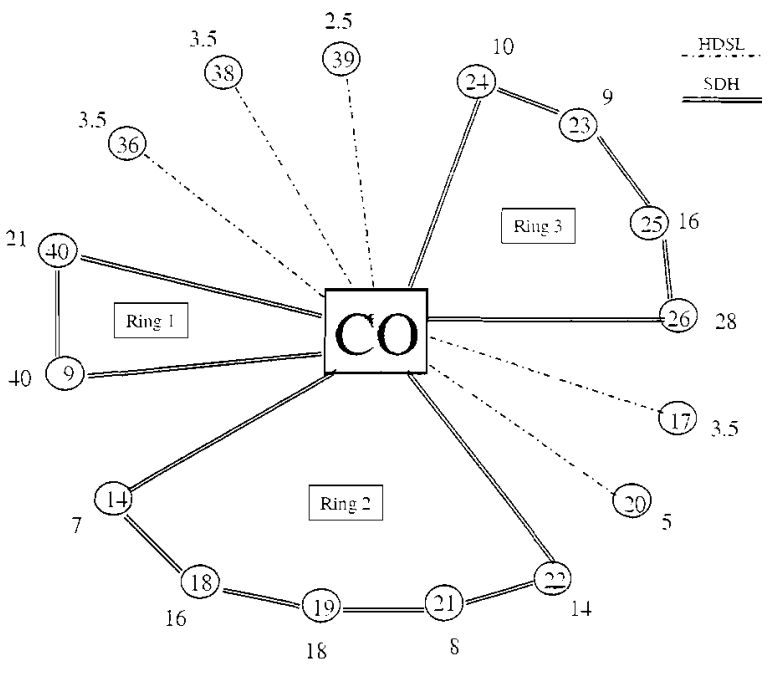

Figure 8. Topology for $0 \leq \lambda \leq 0.368$ (for $\lambda=0, \cos t=13.250$ ).

Up to what $\lambda$ value does this solution (topology) remain the same? This is a parametric programming matter, worsened by the fact we have demand values as variables taken from intervals. Binary variables also make difficult the analysis of the problem [21]. However, the cost structure and equipment's capacities give useful information that can be used while performing such an analysis. Let us see: growing of demand may be absorbed in three ways:

a) taking advantage of the idle capacity of the equipment: without changes of cost or topology;

b) installing HDSL equipment: as these systems don't have fixed cost, they imply changing cost but not necessarily topology;

c) installing new equipment and/or withdrawing equipment that has fixed cost: both solution cost and topology change.

Demand variation may also be in the decreasing way, given that we have intervals. Nevertheless, the reasoning is the same as above.

Let us study with deeper detail how demand varies depending on $\lambda$ parameter. Based on Adamo's equivalent and equations (2I), which describe the intervals of demand for each node, we verify that (Fig. 9):

a) when $\lambda=0$ we have the maximum interval, and the demand may assume any value within this interval. The central value of the interval is exactly the same as $\therefore$ equivalent value $\left(D_{d d}\right)$, while the spread is given by $t_{-}=$ equivalent of the fuzzy number that corresponds to ti: tolerance $\left(T_{-t d}\right)$;

b) as long as $\lambda$ increases, the interval decreases, but it central value remains unaffected;

c) when $\lambda=1$, the interval is reduced to a single point: $i=$ value $D_{\text {dd }}$ given by the equivalent to the node demand (in other words, tolerance is zero).

As long as intervals decrease, the optimization problen: becomes more restricted and the solution cost may $\mathrm{b}=$ greater (because lower limits of demands are increasing). In order to obtain new minimum-cost solutions, some adjustments on the values of effectively met demand are hikely to happen. Of course, tolerances play an important role in this situation.

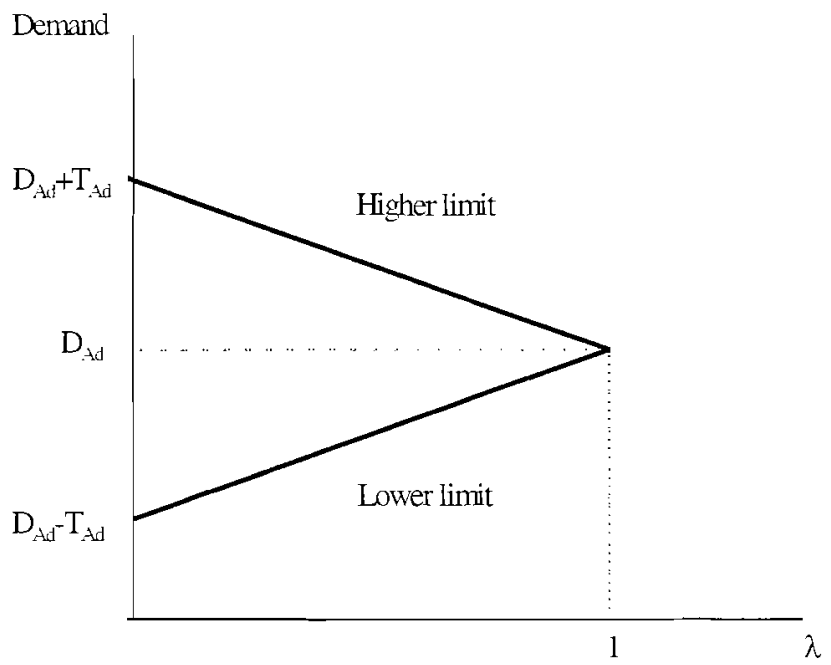

Figure 9. Demand variation with $\lambda$.

The solution will change in an important way when, at each node. demand variation due to $\lambda$ leads to the addition, removal or change of any technology. It is desirable to know for which $\lambda$ value this can occur. In order to do that, a 
detailed analysis must be performed, based on facts like the following ones (which come from cost structure):

a) proportion $(\mathrm{PDH} 1 \times 34 / \mathrm{HDSL})=(1.0 / 0.125)=8.0$ :

b) proportion $(\mathrm{ADM}-21 / \mathrm{HDSL})=(0.74 / 0.125)=5.92$.

It means that, for a node whose demand is lower than 5.92, using HDSL is always the cheapest way. If demand value reaches 5.92 and there is already a SDH ring which the node can join, ADM-21 equipment becomes the most interesting. If there is not such a ring. HDSL continues to be the cheapest one until demand reaches 8 units, when PDH $1 \times 34$ equipment (whenever candidate) is rewarding. This kind of reasoning also holds when we have decreasing demand.

From this point-of-view, let us analyze the solution for $\lambda=0$. Looking again to Fig. 8 and to Table 6 , we see that demands which are met by HDSL (nodes 17, 20, 36, 38 and 39) keep on the lower limit of their intervals, because the objective is to minimize costs, and HDSL costs increase with demand in a linear way. It means that the amount of installed HDSL equipment will be as low as possible. This rule is true, whatever $\lambda$ is. We can conclude that, if among those nodes there is one whose interval's lower limit Inesn't grow up to 5.92 units even when $\lambda=1$, then that node's demand will ever be met by HDSL, whatever $\lambda$ is. In our case study, this happens with nodes 17,38 and 39 .

Nodes 20 and 36 experience a different behavior. By inspecting the lower limits of their intervals for $\lambda=0(5.0$ and 3.5 , respectively) and for $\lambda=1(7.5$ and 6.0$)$, we see that, for some $\lambda, 0<\lambda \leq 1$, the threshold value 5.92 is reached:

a) node 20: linearity of the interval with $\lambda$ allows us to conclude that, at the increase way from 5.0 and 7.5 , the threshold value is reached when $\lambda=0.368$. It means that for $0 \leq \lambda<0.368$ the solution remains unchanged (except for the cost of adding HDSL to the node in order to face the demand growth), at least from this node's perspective;

b) node 36: analogously, we calculate $\lambda=0.968$.

All of the other nodes, in the solution for $\lambda=0$, are served by $\mathrm{SDH}$ rings. This situation requires a different analysis. For each ring, the following question has to be answered: is there a $\lambda$ value for which the total sum of the lower limits to the node demands exceeds the capacity of the ring? If so, what does it happen when $\lambda$ reaches this value?

Again, the analysis will be based on the intervals' lower limits. If with $\lambda=1$ (maximum lower limits) the ring capacity isn't enough to serve the nodes, then the ring will be filled up for some $\lambda, 0<\lambda \leq 1$. Given that in our study each SDH ring"s capacity is 2-Mbps 63 channels, we have:

a) ring 1: for $\lambda=0$, serves nodes 9 and 40 . For $\lambda=1$, lower limits to the demands of these nodes will be respectively 36.0 and 19.5 , making a total of 57.5 , less than 63 . It means that these nodes are not enough to exhaust the ring's capacity;

b) ring 2: for $\lambda=0$, serves nodes $14,18,19,21$ and 22 . For $\lambda=1$, lower limits to the demands of these nodes will make $9.5+14.0+16.0+9.5+12.0=61.0$, and the conclusion is the same as the previous one;

c) ring 3: for $\lambda=0$, serves nodes $23,24,25$ and 26 . For $\lambda=1$, lower limits will make $9.5+8.5+14.0+39.0=71$, which is greater than the capacity of the ring. We need to know for what $\lambda$ the capacity is reached (for what $\lambda$ the lower limits' sum is 63). It is not difficult to calculate $\lambda=0.600$.

Therefore, from the solution with $\lambda=0$ we are able to foresee three situations of important changing: when $\lambda=0.368, \lambda=0.600$ or $\lambda=0.968$. Evidently, $\lambda=0.368$ is the next solution to be analyzed.

With this $\lambda$ value, it becomes more attractive to serve node 20 by a SDH ring. Looking at the set of candidate rings (Table 3 ), we see that ring 2 can be used, if it has idle capacity. For $\lambda=0.368$, the minimum occupancy of the ring due the present nodes $(14,18,19,21$ and 22) is 49.624. It means that node 20 (at this moment with 5.92 , the minimum) can join the ring. The solution for $\lambda=0.368$ has total cost 13.687 (Fig. 10).

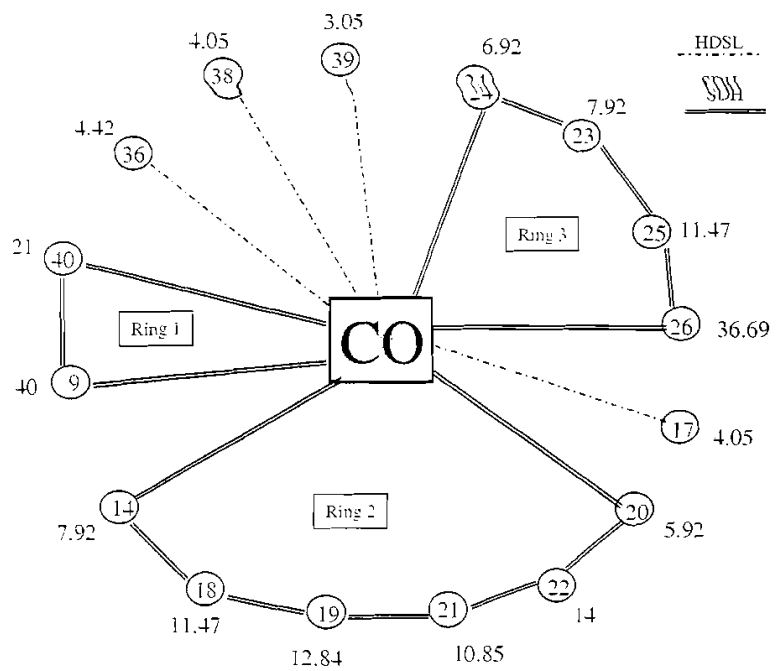

Figure 10. Topology for $0.368 \leq \lambda \leq 0.600$ (for $\lambda=0.368$, $\cos t=13.687$ ).

To this new solution, analyses as the previous ones must be performed. As long as $\lambda$ increases, the network's topology changes in order to maintain the cost as minimal as possible. In this study, four types of topology transitions arise:

a) transition $\mathrm{A}(\mathrm{i}, \mathrm{r})$ : node $\mathrm{i}$ does not use HDSL anymore, and joins ring $\mathrm{Rr}$ :

b) transition B(i,r): node $i$, which already belongs to ring $\mathrm{Rr}$, starts additionally to use HDSL:

In this case, ring $\mathrm{Rr}$ exhausts its capacity. According to the cost structure, it is better (cheaper) to keep nodes in the ring and to meet their exceeding demand by HDSL equipment. This is always possible, because HDSL is offered to all nodes. From the cost point-of-view, it has no difference between to install HDSL at all nodes of ring $\mathrm{Rr}$ or to choose only one node among them to carry the exceeding demand. We adopt the later option.

c) transition $\mathrm{C}(\mathrm{i}, \mathrm{r})$ : node $\mathrm{i}$ leaves ring $\mathrm{Rr}$ and starts to use HDSL only;

In this case, existing SDH equipment at same node in ring $\mathrm{Rr}$ becomes underutilized. For instance, if ring $\mathrm{Rr}$ serves 4 nodes, this will happen when, due to the increase of $\lambda$, the sum of the demands' lower limits for 3 among those nodes reaches $63-5.92=57.08$. At this 
moment, it will not be worthy to pay for SDH equipment to carry less than 5.92 demand units: it is cheaper, to some node, trying to join another ring (if there is one) or to use HDSL.

d) transition D(i): node does not use HDSL anymore, and starts to use PDH only;

In this case, demand at an HDSL-served node is increased up to a value from beyond PDH is rewarding (with the example's cost structure, it happens when the demand reaches 8 units).

Of course, depending on the cost structure, the equipment's capacities, the allowed ways of linking equipment and the candidate rings, other transition types may occur. Nevertheless, the proposed approach holds, and the denotation for transitions can be easily adapted.

Table 7 summarizes the topology transitions we can find in our example.

\begin{tabular}{|c|c|c|}
\hline $\begin{array}{c}\text { Range } \\
\text { for } \lambda\end{array}$ & $\begin{array}{c}\text { Transition } \\
\text { at lower } \lambda\end{array}$ & $\begin{array}{c}\text { Cost } \\
\text { at lower } \lambda\end{array}$ \\
\hline $0.000 \leq \lambda<0.368$ & - & 13.250 \\
\hline $0.368 \leq \lambda<0.600$ & $\mathrm{~A}(20,2)$ & 13.687 \\
\hline $0.600 \leq \lambda<0.690$ & $\mathrm{~B}(24,3)$ & 13.890 \\
\hline $0.690 \leq \lambda<0.732$ & $\mathrm{C}(24,3)$ & 14.195 \\
\hline $0.732 \leq \lambda<0.782$ & $\mathrm{~B}(20,2)$ & 14.244 \\
\hline $0.782 \leq \lambda<0.800$ & $\mathrm{C}(20,2)$ & 14.433 \\
\hline $0.800 \leq \lambda<0.968$ & $\mathrm{D}(24)$ & 14.460 \\
\hline $0.968 \leq \lambda \leq 1.000$ & $\mathrm{~A}(36,1)$ & 14.660 \\
\hline
\end{tabular}

Table 7. Topology transitions.

Fig. 8 and Figs. 10 to 17 present the network topologies that hold for each $\lambda$ range. Whenever transitions $B(i, r)$ take place, the exceeding demand is represented by the symbol $\Delta$ at the node which starts to use HDSL.

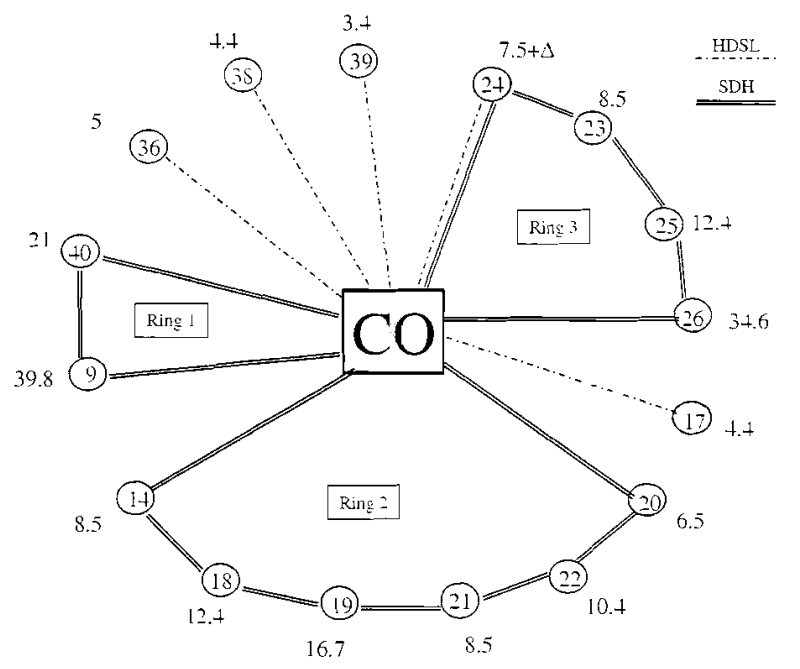

Figure 11. Topology for $0.600 \leq \lambda \leq 0.690$ (for $\lambda=0.600$, cost $=13.890$ ).

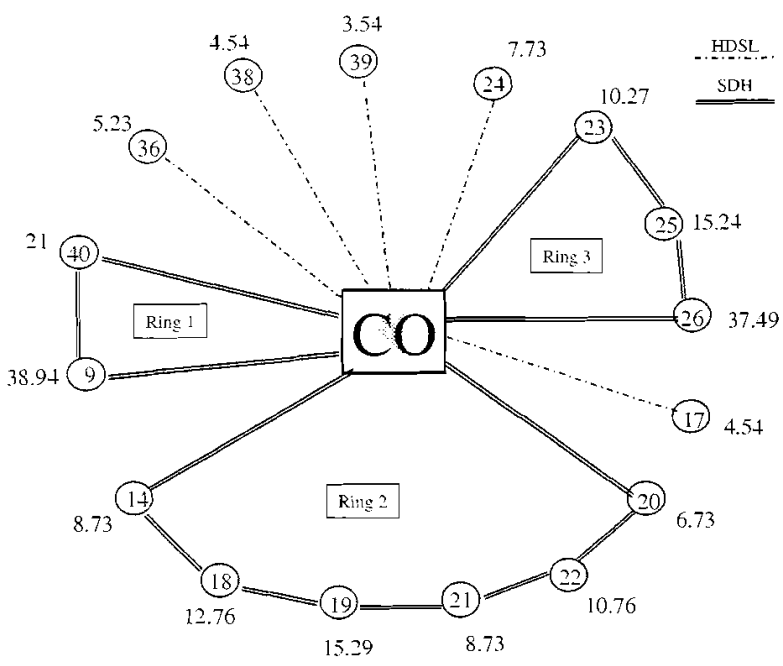

Figure 12. Topology for $0.690 \leq \lambda \leq 0.732$ (for $\lambda=0.690$, cost $=14.195$ ).

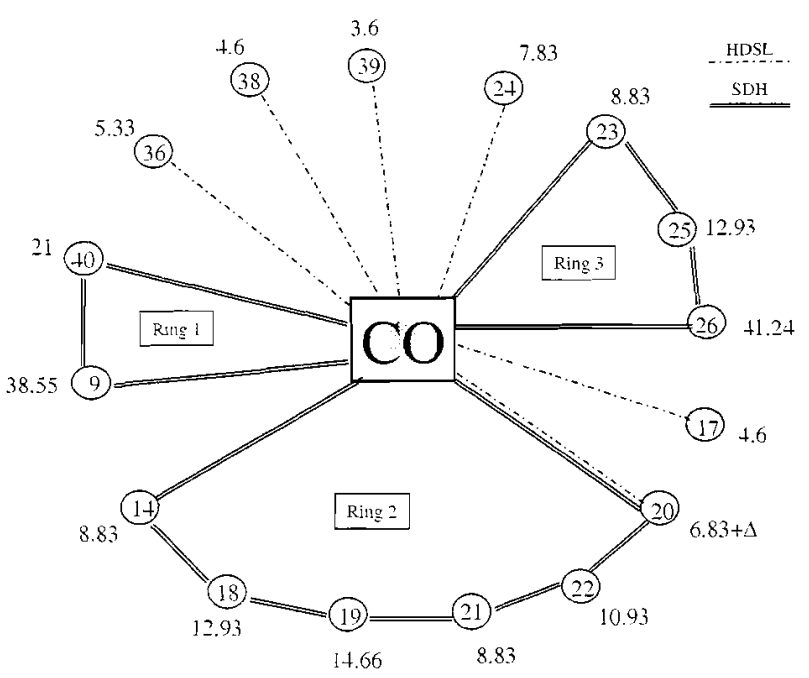

Figure 13. Topology for $0.732 \leq \lambda \leq 0.782$ (for $\lambda=0.732$, $\cos t=14.244)$.

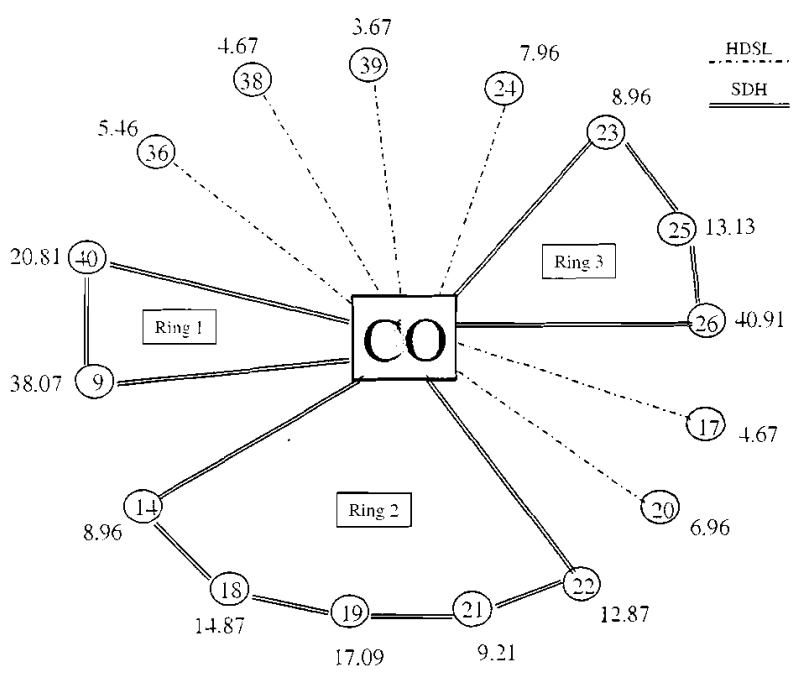

Figure 14. Topology for $0.782 \leq \lambda \leq 0.800$ (for $\lambda=0.782$, $\cos t=14.433$ ). 


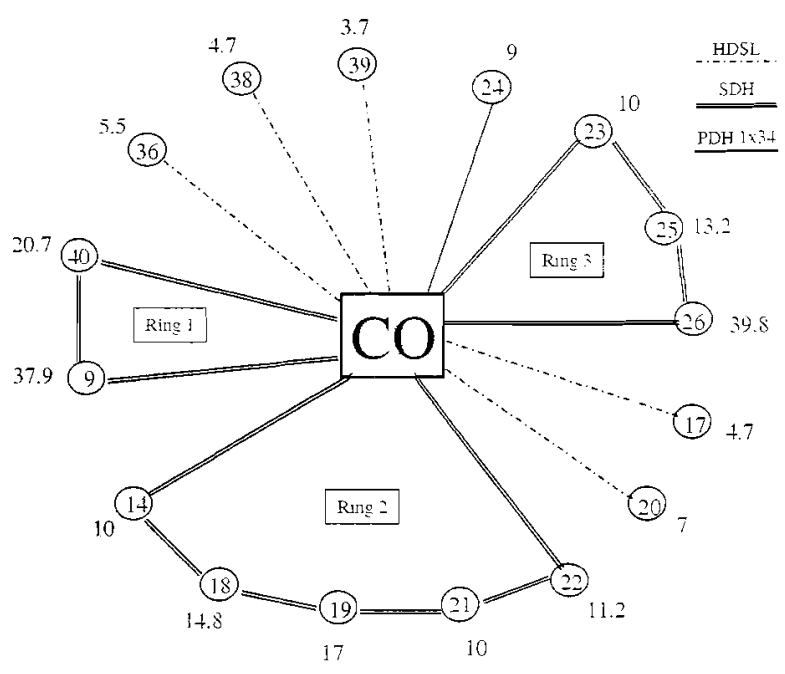

Figure 15. Topology for $0.800 \leq \lambda \leq 0.968$ (for $\lambda=0.800$, cost $=14.460)$.

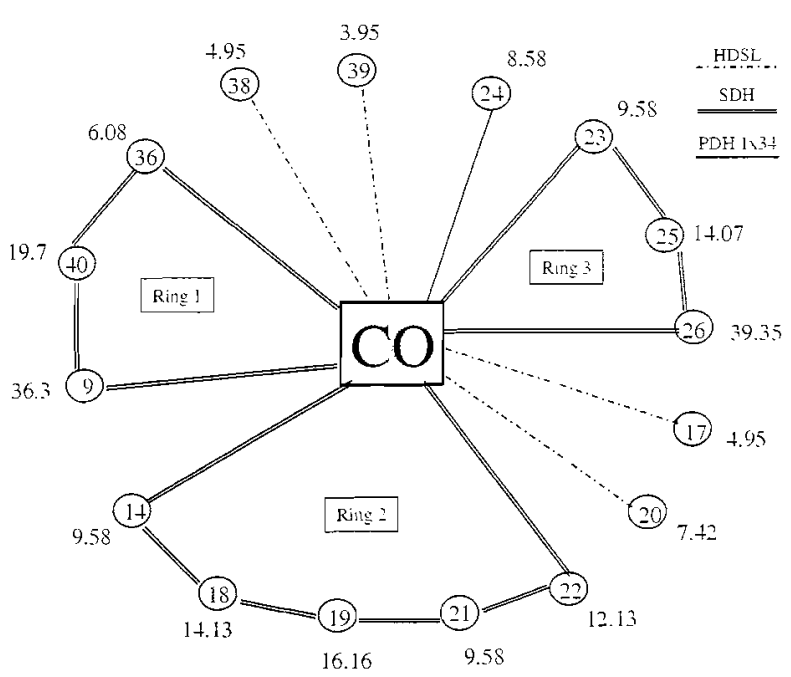

Figure 16. Topology for $0.968 \leq \lambda \leq 1$ (for $\lambda=0.968$, $\cos t=14.660)$.

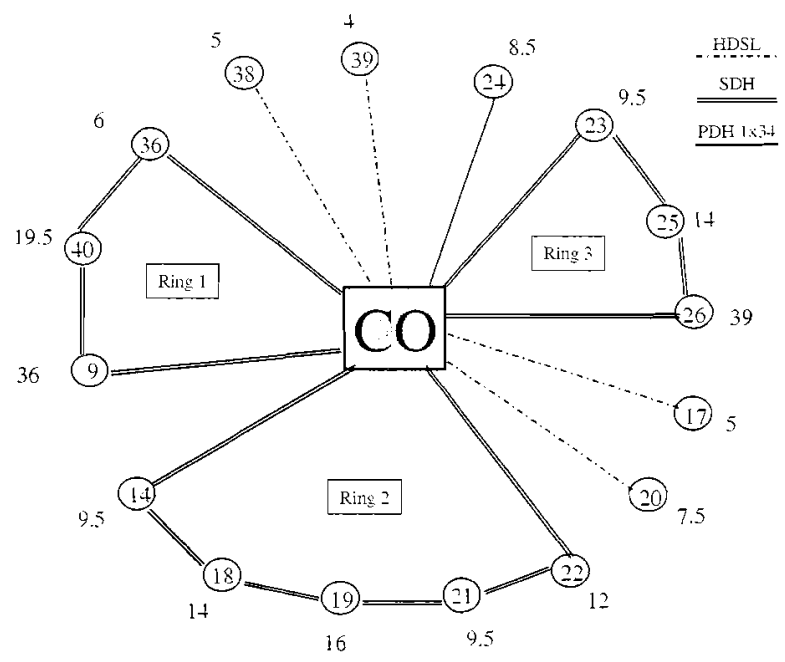

Figure 17. Network for $\lambda=1(\cos t=14.688)$.

Through this analysis we get the cost evolution depending on $\lambda$ parameter (Fig. 18). As we should expect, cost evolves in an increasing way, due the incremental, demand-growth proportional deployment of HDSL equipment.

Table 8 shows, for each transition, the use of each technology in both meeting of the demand and total cost composition. For each $\lambda$ value, cost is at the first line, while the met demand is at the second line. We can see that SDH rings always serve most of the demand, among $84 \%$ (184.60/219.20) and 92\% (187.00/202.57). Total cost due to SDH systems stands among $71 \%(10.26 / 14.46)$ and $86 \%$ (11.74/13.69), respectively. On the other hand, HDSL equipment, whose amount is non-negligible in the solution., from $8 \%(15.57 / 202.57)$ to $15 \%(33.39 / 218.27)$, are proportionally the most expensive with regarding to total cost: from $14 \%(1.95 / 13.69)$ to $29 \%(4.17 / 14 / 43)$.

\begin{tabular}{|c|c|c|c|c|}
\hline & \multicolumn{4}{|c|}{ Cost and met demands } \\
\hline & PDH & SDH & HDSL & Total \\
\hline \multirow{2}{*}{$\lambda_{2}=0.000$} & 0.00 & 11.00 & 2.25 & 13.25 \\
\hline & 0.00 & 187.00 & 18.00 & $205 . \overline{00}$ \\
\hline \multirow{2}{*}{$\lambda=0.368$} & 0.00 & 11.74 & 1.95 & 13.69 \\
\hline & $0.0 \overline{0}$ & 187.00 & 15.57 & 202.57 \\
\hline \multirow{2}{*}{$\hat{\lambda}=\mathbf{0 . 6 0 0}$} & 0.00 & 11.74 & 2.15 & 13.89 \\
\hline & 0.00 & 186.80 & 17.20 & 204.00 \\
\hline \multirow{2}{*}{$\lambda=0.690$} & 0.00 & 11.00 & 3.20 & 14.20 \\
\hline & 0.00 & 185.94 & 25.58 & 211.52 \\
\hline \multirow{2}{*}{$\lambda=\mathbf{0 . 7 3 2}$} & 0.00 & 11.00 & 3.25 & 14.25 \\
\hline & 0.00 & 185.55 & 25.96 & 211.51 \\
\hline \multirow{2}{*}{$\lambda=\mathbf{0 . 7 8 2}$} & 0.00 & 10.26 & 4.17 & 14.43 \\
\hline & 0.00 & 184.88 & 33.39 & 218.27 \\
\hline \multirow{2}{*}{$\lambda=0.800$} & 1.00 & 10.26 & 3.20 & 14.46 \\
\hline & 9.00 & $18+.60$ & 25.60 & $219 . \overline{20}$ \\
\hline \multirow{2}{*}{$\lambda=\mathbf{0 . 9 6 8}$} & 1.00 & 11.00 & 2.66 & 14.66 \\
\hline & 8.58 & 186.66 & 21.27 & 216.51 \\
\hline \multirow{2}{*}{$\lambda=1.000$} & 1.00 & 11.00 & 2.69 & 14.69 \\
\hline & 8.50 & 185.00 & $21 . \overline{50}$ & 215.00 \\
\hline
\end{tabular}

Table 8. Use of technologies in the solutions.

\section{Cost}

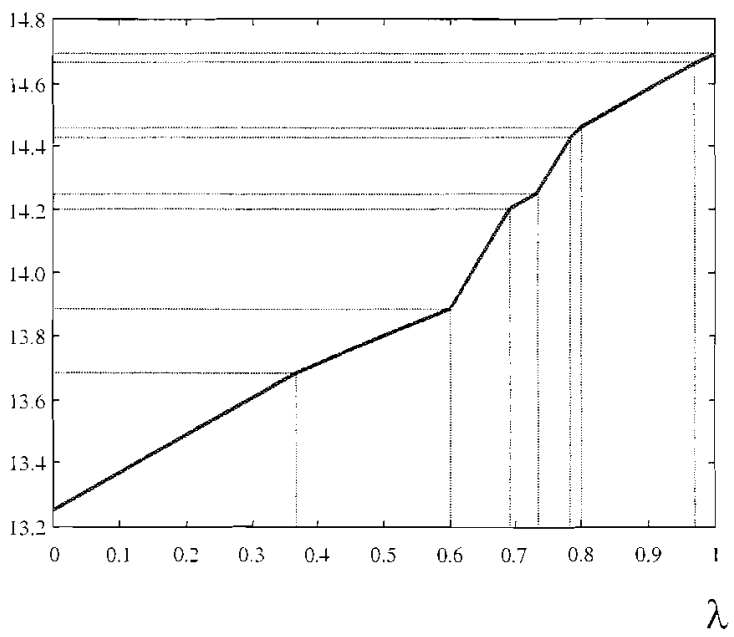

Figure 18. Cost variation according to $\lambda$ parameter.

By inspecting both Fig.18 and Table 8, we see that cost increases in a harder way when some node leaves a SDH ring and starts using only HDSL (ranges $0.600 \leq \lambda \leq 0.690$ 
and $0.732 \leq \lambda \leq 0.782$ ). We conclude that, if there were another SDH ring to serve that node, then the cost evolution would be softer. Therefore, on larger networks, with more options for installing rings, the use of HDSL is likely to decrease, and HDSL is restricted to serve low demands.

Moreover, it should be noted that, at greater demand settings, SDH rings aren't enough in our example. PDH equipment, even at a high cost, must be used. At $\lambda=0.800$, PDH's modularity leads to a lower cost-per-channel than HDSL's one. Thus, the planner must enrich the set of candidate rings whenever possible.

It may also be of planner's interest to know how much demand the solution (topology) could meet at the same cost. Table 9 presents the topologies $(\lambda)$, their total capacities (sum of individual equipment's capacity), besides the demand related to each level of $\lambda$ (all the demand is met). Due the cost minimization criterion and the allowing of non-integral values to demands, we always have low idleness, around $1 \%$. The idleness only changes to $5 \%$ when a piece of $\mathrm{PDH}$ equipment is used $(0.800 \leq \lambda \leq 1)$.

\begin{tabular}{|c|c|c|}
\hline$\lambda$ & Total demand & Total Capacity \\
\hline 0.000 & 205.00 & 207.00 \\
\hline 0.368 & 202.57 & 204.57 \\
\hline 0.600 & 204.00 & 206.20 \\
\hline 0.690 & 211.52 & 214.58 \\
\hline 0.732 & 211.51 & 214.96 \\
\hline 0.782 & 218.27 & 222.39 \\
\hline 0.800 & 219.20 & 230.60 \\
\hline 0.968 & 216.51 & 226.27 \\
\hline 1.000 & 215.00 & 226.50 \\
\hline
\end{tabular}

Table 9. Total demand and total capacity of the networks.

The above case study was based on Adamo's equivalent. Many other methods, such as Yager-3, can be used instead, leading to conceptually similar results. However, in order to simplify solving and analysis, it is always desirable that the adopted method keeps the linear feature of the problem.

\section{CONCLUSION}

We have presented a model to the telecommunications networks planning when there is uncertainty concerning to the adopted demand values. We have focused specifically on cable-based access networks whose subscribers offer demand values of 2 Mbps or higher. These networks accept a lot of different equipment and services. The model allows competition between optical (PDH, SDH, etc.) and copperbased technologies (HDSL), and takes into account the topologies related with each technology.

With this model, the planner does not need to stipulate exact values as demands anymore. Uncertainty is approached by means of fuzzy sets and fuzzy numbers concepts. Demand values are expressed as intervals with tolerances. In order to deal with uncertainty, parametric equivalents are used. There are several applicable equivalents; each of them transforms the problem in its own manner, thus leading to distinct models

We have reported the application of the model to a business area network. Our experiments were guided by the criterion of minimum cost. We have enforced the fact that using parameters allows us to perform important analyses. It becomes possible to foresee cost evolution and technology transitions due to the demand behavior. Parametric analysis, while complicated by the existence of binary variables in the problem, is clearly practicable by exploring both cost structure and equipment features.

Results of the experiments combine $\mathrm{PDH}, \mathrm{SDH}$, and HDSL technologies. With the adopted cost structure, SDH is the chief technology. HDSL is confined to serve low demands. PDH equipment is only used when SDH options are not available anymore and the ratio cost/demand is attractive.

In the explained model we have used cost minimization as the criterion for choosing optimal plans or, in other words, the best configuration of technologies and topology. For achieving this purpose, a linear mixed problem was solved. However, the model can be adjusted in order to fit other criteria, such as the total slack of the solution, or the level of protected demands.

Difficulties while forecasting demands often lead the planner to handle imprecise values. Therefore, the model we have presented surely may be used as a support tool to the planning of optical telecommunications networks.

\section{REFERENCES}

[1] TELEBRÁS, Design Procedures for Business-Oriented Access Networks (in Portuguese), Practice SDT-210-001-601, December 1993.

[2] J. R. F. Formigoni, H. M. F. Tavares and R. V. Ribeiro, "A Software Planning Tool for a Business Oriented Optical Access Network - PREST", Procs. IEEE GLOBECOM'95, Singapore, p. 1920-1924, November 1995.

[3] J. R. F. Formigoni, R. V. Ribeiro and H. M. F. Tavares, "Optical Access Network: Optimal Deployment", Procs. $5^{\text {th }}$ Intl. Conf. Teleconmunn. Syst. - Modeling and Analysis, Nashville, p. 210-213, March 1997.

[4] C. M. F. Carlson, J. R. F. Formigoni and H. M. F. Tavares, "Planning of Optical Fiber Telecommunication Networks: An approach based on Fuzzy Sets", Procs. $7^{\text {th }}$ IFSA World Congress, Prague, vol. II, p. 543-549, June 1997.

[5] W. Pedrycz and F. Gomide, An Introduction to Fu-zy Sets: Analysis and Design, MIT Press, Cambridge, 1998.

[6] R. E. Bellman and L. A. Zadeh, "Decision-Making in a Fuzzy Environment", Mgmt. Sci., vol.17, no. 4, p. B141-B164, 1970.

[7] C. M. F. Carlson, J. R. F. Formigoni and H. M. F. Tavares, "Dealing with Fuzzy Costs in Telecommunications Network Design", Procs FUZZ'IEEE'98, Anchorage, vol. I.. p. 634639, May 1998.

[8] C. M. F. Carlson, J. R. F. Formigoni and H. M. F. Tavares, "Key Customers Serving under Uncertain Costs: Optical Systems versus HDSL" (in Portuguese), Ann. XV Brazilian Symp. Telecommun., Recife, p. 40-44. September 1997.

[9] G. Bortolan and R. Degani, "A review of some methods for ranking fuzzy subsets", Fuzzy Sets Syst, vol. 15, p. 1-19, 1985.

[10] H. Tanaka, H. Ichihashi and K. Asai, "A Formulation of Fuzzy Linear Programming Problems based on Comparison of Fuzzy Numbers", Control Cybernet., vol. 3, p. 185-194, 1984.

[11] S. V. Ahamed, P. L. Gruber and J.-J. Werner, "Digital Subscriber Line (HDSL and ADSL) Capacity of the Outside Loop Plant", IEEE JSAC, vol. 13, no. 9, p. 1540-1549, 1995. 
[12] R. K. Ahuja, T. L. Magnanti and J. B. Orlin. Network flows: theory, algorithms, and applications, Prentice Hall, Englewood Cliffs (NJ), 1993.

[13] A. Balakrishnan, T. L. Magnanti, A. Shulman and R. T. Wong, "Models for Planning Capacity Expansion in Local Access Telecommunication Networks", Ann. Oper. Res., vol. 33, p. 239-284, I991.

[14] C. Jack, S.-R. Kai and A. ShuIman, "NETCAP - An Interactive Optimization System for GTE Telephone Network Planning", Interfaces, vol. 22. no. 1, p. 72-89, 1992.

[15] EURESCOM, "Project P614 - Implementation Strategies for Advanced Access Networks". Eurescom Deliverable 10, 1998.

[16] M. A. DeSousa, C. M. F. Carlson, J. R. F. Formigoni and R. V. Ribeiro, "Revenue-oriented Planning of the Access Network" (in Portuguese), Ann. XVII Brazilian Symp. Teleconnum., Vila Velha, p. 389-394, September 1999.

[17] R. R. Yager, "A Procedure for Ordering Fuzzy Subsets of the Init Interval", Information Sci, vol. 24, p. 143-161, 1981.

[18] J. M. Adamo, "Fuzzy decision trees", Fu-zy Sets Syst.. vol. 4, p. 207-209, 1980.

[19] M. Delgado, J. L. Verdegay and M. A. Vila, "A general model for fuzzy linear programming". Fu-ry Sets Syst., vol. 29, p. 21-29, 1989.

[20] L. Campos and J. L. Verdegay, "Linear programming problems and ranking of fuzzy numbers", Fu-zy Sets Syst. vol. 32, p. 1-11, 1989.

[21] B. Bank, J. Guddat. D. Klatte, B. Kummer and K. Tammer, Non-Linear Parametric Optimization, Birkhäuser Verlag, Basel, 1983.
Carlos Magnus F, Carlson is a professor at the University Center of Rio Preto - UNIRP, Brazil, since 1992. He holds a doctorate in Electrical Engineer (UNICAMP, 1998). His main research interest is the application of Operations Research techniques to the telecommunications planning, steel industry, and transportation.

Hermano de Medeiros F. Tavares is a professor at the Electrical and Computer Engineering School of the State University of Campinas - DENSIS/FEEC/UNICAMP, Brazil, since 1971. He is also the current UNICAMP's Chancellor (1998-2002). He holds a doctorate in Electronics Engineering (Toulouse. 1968), and has been working with telecommunications planning for several years.

José Reynaldo F. Formigoni is a member of the consulting staff at the CPqD Foundation - IT \& Telecom Solutions, Campinas, Brazil, since 1992. He holds a MSc. in Electrical Engineering (UNICAMP, 1995). His main research interests are the evolution of cellular wireless systems, strategic planning and optimization. 